\title{
Características morfogênicas, estruturais e padrões demográficos de perfilhos em pastagem de capim-andropógon sob diferentes ofertas de forragem
}

\section{Morphogenetic characteristics and demographic patterns of tillers on andropogon grass under different forage allowances}

\author{
Daniel Louçana da Costa Araújo ${ }^{1 *}$; Maria Elizabete de Oliveira ${ }^{2}$; \\ João Batista Lopes²; Arnaud de Azevêdo Alves²; Marcônio Martins Rodrigues; \\ Raniel Lustosa de Moura ${ }^{4}$; Maurílio Souza dos Santos ${ }^{5}$
}

\section{Resumo}

\begin{abstract}
Objetivou-se avaliar as características morfogênicas, estruturais e os padrões demográficos de perfilhamento do capim Andropogon gayanus Kunth var. Bisquamulatus (Hochst) Hack. cv. Planaltina, submetido a três ofertas de forragem: 11,15 e $19 \%$ do PV, sob lotação contínua de caprinos. O delineamento experimental para avaliação das características morfogênicas do pasto foi o de blocos ao acaso (dois), com seis repetições (touceiras) dentro do bloco. Para a avaliação da dinâmica de perfilhamento e densidade populacional adotou-se o delineamento experimental em blocos ao acaso (dois), em esquema de parcelas subdivididas. Nas parcelas, avaliou-se o efeito das ofertas de forragem e, nas subparcelas, os meses: abril, maio e junho. As ofertas de forragem não influenciaram as taxas de alongamento foliar, de senescência foliar e o número de folhas vivas. A taxa de aparecimento de folhas foi maior nas ofertas de 11 e 15\% PV. O manejo do pasto com oferta de forragem $19 \%$ do PV proporciona aumento na taxa de alongamento do colmo, na duração de vida das folhas e no comprimento das folhas e colmos. O número de perfilhos vegetativos e as taxas de aparecimento e sobrevivência de perfilhos não são influenciados pela oferta de forragem de 11 a $19 \%$ do PV.

Palavras-chave: Alongamento de colmo, lotação contínua, perfilhamento, senescência foliar
\end{abstract}

\begin{abstract}
The objective of this study was to evaluate the morphogenetic and structural characteristics and the demographic patterns of tillering in the grass Andropogon gayanus Kunth var. Bisquamulatus (Hochst) Hack. cv. Planaltina subjected to three forage allowances: 11, 15 and 19\% of the LW, under continuous grazing by goats. The experimental design for the evaluation of the pasture morphogenetic characteristics was set in (two) random blocks, with six replications (tussocks) within the block. To evaluate the tillering dynamics and population density, we adopted the experimental design of (two) random blocks,
\end{abstract}

${ }^{1}$ Eng $^{\circ}$ Agr ${ }^{\circ}$, Prof., Dept ${ }^{\circ}$ de Zootecnia, Universidade Federal do Piaú, UFPI, Teresina, PI. E-mail: danielloucana@hotmail.com

2 Profs., Programa de Pós-Graduação em Ciência Animal, UFPI, Teresina, PI. E-mail: maeliz@uol.com.br; lopesjb@uol.com.br; arnaud@ufpi.edu.br

${ }^{3}$ Eng $^{\text {O }}$ Agr $^{\circ}$, Dr. em Ciência Animal, Universidade Federal do Maranhão, UFMA, Chapadinha, MA. E-mail: marnunes07@yahoo. com.br

${ }^{4}$ Zootecnista, Discente do Curso de Doutorado em Ciência Animal, UFPI, Teresina, PI. E-mail: mourabio@yahoo.com.br

${ }^{5}$ Médica Veterinária, Dr ${ }^{\mathrm{a}}$ em Ciência Animal, Universidade Estadual do Piaú, UESPI, Corrente, PI. E-mail: maurílio.vet@ hotmail.com

* Autor para correspondência 
in a split-plot arrangement. In the plots, we evaluated the effect of forage allowances and in the subplots, the months of April, May and June. Forage allowances did not affect the leaf elongation rate, leaf senescence or the number of live leaves. The leaf appearance rate was highest at the masses of 11 and $15 \%$ of the LW. Managing the pasture with a forage allowance of $19 \%$ of the LW increases the stem elongation rate, leaf lifespan and the lengths of leaf and stem. The number of vegetative tillers and the tiller appearance and survival rates are not affected by the forage allowances from 11 to $19 \%$ of the LW.

Key words: Continuous grazing, leaf senescence, stem elongation, tillering

\section{Introdução}

O manejo de pastejo objetiva maximizar a transformação da forragem produzida em produto animal, mantendo-se a perenidade do pasto, através da contínua emissão de folhas e perfilhos após o pastejo, restaurando a área foliar da planta. Para isso, é essencial o conhecimento da dinâmica dos processos de crescimento e desenvolvimento das plantas que compõem a pastagem (CASAGRANDE et al., 2010).

A dinâmica de produção de forragem no pasto pode ser compreendida pelo estudo da morfogênese. As principais relações entre características morfogênicas e estruturais das gramíneas forrageiras em estádio vegetativo foram apresentadas por Chapman e Lemaire (1993). Segundo estes autores, as características morfogênicas, tais como alongamento de folhas e colmos, aparecimento de folhas e duração de vida das folhas, determinam as três principais características estruturais do pasto, que são tamanhos da folha, número de folhas vivas e densidade populacional.

As variáveis morfogênicas são geneticamente determinadas e podem ser influenciadas por fatorxes ambientais, como temperatura, luminosidade, disponibilidade de água e de nutrientes (ROMA et al., 2012; BASSO et al., 2010; SILVEIRA et al., 2010; FERLIN et al., 2006), enquanto as variáveis estruturais são influenciadas por alterações nas respostas morfogênicas e pela frequência e intensidade de pastejo (DONEDA; SANTOS; SBRISSIA, 2012; BARBOSA et al., 2011).

Os estudos dessas variáveis geram conhecimentos básicos necessários para definições de estratégias de manejo para plantas forrageiras. A adequação de níveis de oferta de forragem à demanda dos animais a partir de resultados de estudos das características morfogênicas e estruturais de gramíneas forrageiras tropicais tem permitido o estabelecimento de ajustes e definições de estratégias eficazes de manejo do pastejo, e assim diferenças no desempenho de bovinos (CASAGRANDE et al., 2010; BARBOSA; NASCIMENTO; CECATO, 2006). Em face ao exposto, torna-se relevante estabelecer estudos com outras espécies animais, tais como caprinos, em decorrência do comportamento diferenciados destes animais. Assim, o processo de seletividade da desfolha realizada pelos caprinos, pode ao longo do tempo dar origem a diferenças na estrutura e composição do pasto.

Assim, realizou-se este estudo com o objetivo de avaliar as características morfogênicas, estruturais e os padrões demográficos de perfilhamento do dossel de Andropogon gayanus cv. Planaltina, submetido a diferentes ofertas de forragem, sob lotação contínua com caprinos.

\section{Material e Métodos}

O experimento foi conduzido no Setor de Caprinocultura do Departamento de Zootecnia do Centro de Ciências Agrárias da Universidade Federal do Piauí, de março a junho de 2011 (final do período das chuvas), em área situada no município de Teresina - PI ( $05^{\circ} 05^{\prime} 21^{\prime \prime} \mathrm{S}, 42^{\circ} 48^{\prime} 07^{\prime \prime} \mathrm{W}$ e $74,4 \mathrm{~m}$ de altitude). O clima do local, segundo a classificação de Köppen, é do tipo Aw, clima tropical e chuvoso (megatérmico), com inverno seco e verão chuvoso. As informações de precipitação pluviométrica e 
temperaturas mínimas e máximas durante o período experimental encontram-se na Figura 1.

O solo da área experimental é do tipo Latossolo Vermelho-Amarelo, textura média, distrófico, classificado segundo metodologia proposta pela EMBRAPA (2006). Antes da implantação do experimento, foram colhidas amostras de solo na camada de 0 a $20 \mathrm{~cm}$ para determinação da fertilidade, cuja análise apresentou o seguinte resultado: $\mathrm{pH}\left(\mathrm{H}_{2} \mathrm{O}\right)=5,5 ; \mathrm{Ca}\left(\mathrm{cmol}_{\mathrm{c}} / \mathrm{dm}^{3}\right)=0,2$; $\mathrm{Mg}\left(\mathrm{cmol}_{\mathrm{c}} / \mathrm{dm}^{3}\right)=0,1 ; \mathrm{Al}\left(\mathrm{cmol}_{\mathrm{c}} / \mathrm{dm}^{3}\right)=0,2 ; \mathrm{K}$ $\left(\mathrm{cmol}_{\mathrm{c}} / \mathrm{dm}^{3}\right)=0,12 ; \mathrm{H}+\mathrm{Al}\left(\mathrm{cmol}_{\mathrm{c}} / \mathrm{dm}^{3}\right)=3,7$; soma de bases $\left(\mathrm{cmol}_{\mathrm{c}} / \mathrm{dm}^{3}\right)=0,43$; CTC $\left(\mathrm{cmol}_{\mathrm{c}} / \mathrm{dm}^{3}\right)=$ 4,0; saturação por alumínio $(\%)=32,0$; saturação por bases $(\%)=10,0 ; \mathrm{P}-$ Mehlich-1 $\left(\mathrm{mg} / \mathrm{dm}^{3}\right)=$ 2,40 .

Figura 1. Precipitação pluviométrica, temperatura média, máxima e mínima no período de março a junho de 2011, em Teresina, PI.

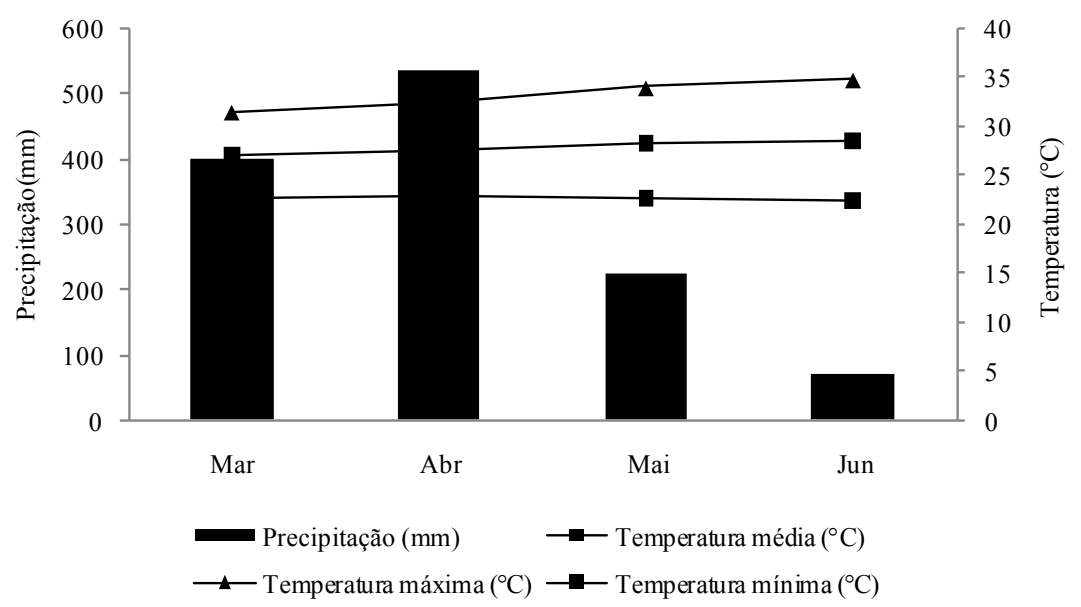

Fonte: Elaboração dos autores.

A área experimental foi implantada no ano de 2000 e semeada com capim-andropógon (Andropogon gayanus Kunth var. Bisquamulatus (Hochst) Hack. cv. Planaltina), sendo utilizada até o período antecedente ao experimento em pastejo rotacionado por caprinos. Em dezembro de 2010 dimensionou-se a área experimental de 1,44 ha, dividindo-a em três piquetes de 0,18; 0,24 e 0,30 ha para as ofertas de forragem de $11 ; 15$ e $19 \%$ do PV, respectivamente, em dois blocos. Em janeiro de 2011, foi realizada calagem, com aplicação de 1,1 t/ha de calcário dolomítico objetivando elevar a saturação por bases para 35\%. Em março de 2011, realizou-se corte, com roçadeira mecânica, para uniformização da altura do pasto, em média de $20 \mathrm{~cm}$, e adubouse em cobertura com 50, 40 e $40 \mathrm{~kg} /$ ha de $\mathrm{N} ; \mathrm{P}_{2} \mathrm{O}_{5}$ e $\mathrm{K}_{2} \mathrm{O}$, na forma de uréia, superfosfato simples e cloreto de potássio, respectivamente. Para controle do número de espécies indesejáveis foi realizada aplicação de herbicida diclorofenoxiacético em área total, na dosagem de $2,4 \mathrm{~kg}$ de i.a/ha.

O delineamento experimental para avaliação das características morfogênicas do pasto foi o de blocos ao acaso (dois), com três tratamentos (três ofertas de forragem) e seis repetições dentro do bloco (touceiras). Para avaliação da dinâmica de perfilhamento e densidade populacional adotouse o delineamento experimental em blocos ao acaso com os tratamentos no esquema de parcelas subdivididas. $\mathrm{Na}$ parcela principal alocoram-se ofertas de forragem $(11,15$ e $19 \%$ do $\mathrm{PV} /$ dia $)$ e nas subparcelas, os meses: abril, maio e junho. As ofertas efetivas, no entanto, não foram iguais às planejadas, sendo observados valores de 10, $14 \mathrm{e}$ 
$20 \%$ do PV/dia.

No pastejo foram utilizados caprinos machos, mestiços, castrados, com aproximadamente quatro meses de idade e com peso vivo inicial 22,8 43,2 kg. Adotou-se o método de pastejo em lotação contínua, ajustada a cada 28 dias de acordo com a disponibilidade de massa de forragem, segundo a técnica "put-and-take" (MOTT; LUCAS, 1952). Em cada unidade experimental, animais traçadores, em número de cinco, foram mantidos, e animais reguladores foram adicionados ou retirados no decorrer das avaliações, para ajuste da taxa de lotação de acordo com a oferta estipulada. Para controle da oferta de forragem, os animais foram pesados no início do período de pastejo e a cada 28 dias, após 14 horas de jejum.

A taxa de lotação (TL) foi calculada considerando a unidade animal (UA) como sendo $450 \mathrm{~kg}$ de PV, pela fórmula: $\mathrm{TL}=\mathrm{UAt} /$ área em que UAt $=$ unidade animal total; área = área experimental total, em ha. A oferta de forragem (OF) foi calculada pela fórmula: $\mathrm{OF}=(\mathrm{DISP} /(\mathrm{PV} / 100) / \mathrm{DIA}$ em que: $\mathrm{OF}$ = oferta de forragem, em kg MS/ $100 \mathrm{~kg}$ PV.dia; DISP $=$ disponibilidade de forragem em $\mathrm{kg}$ de MS/ ha; $\mathrm{PV}=$ peso vivo dos animais; DIA = duração do período experimental em número de dias (ALLEN et al., 2011).

Características estruturais do pasto foram avaliadas a cada 28 dias. A altura do dossel foi determinada utilizando-se uma régua de madeira com 2 metros de comprimento graduada em centímetros, medindo-se 30 pontos aleatórios por piquete. A altura de cada ponto correspondeu à altura média do dossel em torno da régua (plano de visão).

As características morfogênicas dos pastos foram avaliadas por meio do monitoramento em cinco perfilhos marcados com auxílio de fios coloridos em seis touceiras por tratamento e por bloco, totalizando 60 perfilhos por tratamento. As avaliações foram realizadas a cada três dias, durante 28 dias no mês de maio, período chuvoso. Foi contado o número de folhas em cada perfilho e em cada uma das folhas foi avaliado o comprimento foliar; classificação de folha quanto ao estádio (em expansão, expandida, senescente e morta). As folhas foram consideradas em expansão, quando suas lígulas não estavam expostas; expandida, quando a lígula estava completamente exposta; senescente, quando parte da folha apresentava sinais de senescência e mortas quando mais de $50 \%$ da folha estava comprometida pela senescência.

O comprimento das lâminas foliares e do colmo dos perfilhos marcados foram medidos com uma régua milimetrada. O comprimento das folhas expandidas foi medido da ponta da folha à lígula. No caso de folhas em expansão, o mesmo procedimento foi adotado, porém considerou-se a lígula da última folha expandida como referencial de mensuração (DURU; DUCROCQ, 2000a). Para as folhas em senescência, ao invés da ponta da folha, considerou-se o ponto até onde o processo de senescência (amarelecimento com posterior enegrecimento) avançou (parte verde da lâmina foliar). O comprimento do colmo correspondeu à distância da superfície do solo à lígula da folha mais jovem completamente expandida.

De posse dessas informações, calcularam-se os parâmetros: taxa de aparecimento foliar (TApF, folhas/ perfilhodia): número de folhas surgidas por perfilho dividido pelo número de dias do período de avaliação; filocrono (FIL, dias/folha.perfilho): inverso da taxa de aparecimento foliar; taxa de alongamento foliar (TAlF, cm/folha.dia): somatório do alongamento de lâmina foliar por perfilho dividido pelo número de dias de avaliação; taxa de alongamento de colmo (TAlC, cm/perfilho.dia): somatório do alongamento de colmo por perfilho dividido pelo número de dias de avaliação; número de folhas vivas expandidas por perfilho (NFVe): número médio de folhas por perfilho completamente expandidas, incluindo as folhas pastejadas, duração de vida das folhas (DVF, dias): estimada pela equação DVF (dia) = NFVe x FIL (LEMAIRE; CHAPMAN, 1996); taxa de senescência foliar 
(TSF, cm/perfilho.dia): decréscimo do comprimento da parte verde da lâmina foliar, obtida pela diferença entre a mensuração inicial e a final dividida pelo número de dias de avaliação; comprimento final de folha ( $\mathrm{CFF}, \mathrm{cm})$ : comprimento médio das folhas vivas, completamente expandidas e não pastejadas no perfilho; comprimento final do colmo ( $\mathrm{CFC}$, $\mathrm{cm})$ : comprimento médio dos colmos.

A avaliação dos padrões demográficos dos perfilhos e das respectivas taxas de aparecimento, mortalidade, e sobrevivência foi realizada segundo Carvalho et al. (2000), alocando-se quatro anéis de PVC de 0,071 $\mathrm{m}^{2}$ de área, $30 \mathrm{~cm}$ de diâmetro e $10 \mathrm{~cm}$ de altura, por piquete, em áreas representativas da condição média do pasto de cada parcela, segundo avaliação visual da altura e massa de forragem. Os anéis foram introduzidos no solo a $8,0 \mathrm{~cm}$ de profundidade, mantendo-se a $2,0 \mathrm{~cm}$ acima da superfície. Todos os perfilhos mantidos no círculo de PVC foram contados e, a partir daí, foram marcados a cada 28 dias com arame liso revestido de plástico de diferentes cores, que representavam cada geração de perfilhos. A primeira avaliação dos perfilhos foi realizada em abril, e a cada nova avaliação todos os perfilhos marcados eram contados, novos perfilhos eram marcadoss, e os arames dos perfilhos mortos recolhidos. Foram considerados mortos os perfilhos desaparecidos como também os secos ou em estádio avançado de senescência. Dessa forma, os perfilhos pertencentes a todas as gerações foram sempre recontados a cada nova avaliação. O tempo gasto para cada avaliação foi de no máximo dois dias e o intervalo entre avaliações foi de 28 dias e ao fim do período experimental, foram identificadas quatro gerações de perfilhos (G1 a G4).

Com base nas contagens, foram calculadas as taxas de aparecimento (TApPb), sobrevivência $(\mathrm{TSo} P \mathrm{P})$ e mortalidade de perfilhos basilares $(\mathrm{TMoPb})$ :

$\mathrm{TApPb}=\frac{\mathrm{n}^{\mathrm{o}} \text { de perfilhos novos marcados } \mathrm{x} 100}{\mathrm{n}^{\mathrm{o}} \text { de perfilhos vivos na marcação anterior }}$
$\mathrm{TSoPb}=\frac{\mathrm{n}^{\mathrm{o}} \text { de perfilhos sobreviventes } \mathrm{x} 100}{\mathrm{n}^{\mathrm{o}} \text { de perfilhos vivos na marcação anterior }}$

$\mathrm{TMoPb}=100-\mathrm{TSoPb}$

Com as informações obtidas para a $\mathrm{TApPb}$ e $\mathrm{TSoPb}$ de perfilhos calculou-se o índice de estabilidade da população de perfilhos (IEst) pela equação: $\mathrm{P} 1 / \mathrm{P} 0=\mathrm{TSoPb}(1+\mathrm{TApPb})$, em que: $\mathrm{P} 1 /$ $\mathrm{P} 0$ corresponde à proporção entre a população de perfilhos existentes no mês (época) 1 e população existente no mês (época) 0 ; e $\mathrm{TSoPb}$ e $\mathrm{TApPb}$, às taxas de sobrevivência e aparecimento de perfilhos durante esse mesmo período, respectivamente (BAHMANI et al., 2003).

As estimativas de densidade populacional de perfilhos basilares (DPPb) foram obtidas independentemente daquelas de demografia do perfilhamento, devido à reduzida área do anel $\left(0,071 \mathrm{~m}^{2}\right)$ e também para evitar que a manipulação periódica realizada em tais anéis (contagem mensais dos perfilhos) interferisse na estimativa final de densidade populacional. Dessa forma, o número de perfilhos foi obtido por meio da contagem do total de perfilhos contidos no interior de uma armação metálica de $0,0625 \mathrm{~m}^{2}(0,25 \mathrm{~m}$ x $0,25 \mathrm{~m})$ que foi introduzida em quatro touceiras por piquete de forma aleatória a cada 28 dias. Além disso, durante cada procedimento de contagem de perfilhos, foram contabilizados o número de perfilhos com inflorescência visível, para permitir que a proporção desses perfilhos pudesse ser calculada em relação à população total.

Os dados de morfogênese do pasto e para dinâmica de perfilhamento e densidade populacional foram submetidos à analise da variância (Proc GLM) e as médias para morfogênese comparadas pelo teste de Duncan e SNK e para dinâmica de perfilhamento e densidade populacional pelo teste t de Student, a 5\% de probabilidade, utilizando-se o pacote estatístico SAS versão 8.11. 


\section{Resultados e Discussão}

As ofertas de forragem influenciaram as características morfogênicas dos pastos de capimandropógon. Maior valor da taxa de aparecimento de folhas (TApF) correspondeu à oferta de $11 \%$ e $15 \%$, não havendo diferença $(\mathrm{P}>0,05)$ entre as ofertas 15 e 19\% do PV (Tabela 1). Como consequência desse comportamento, foram observados diferenças nos intervalos para aparecimento de folhas, ou seja, no pastejo menos intenso foram necessários 10,5 dias para aparecimento de uma folha, enquanto, na maior intensidade apenas 7,7 dias.

Tabela 1. Características morfogênicas e estruturais de perfilhos de capim-andropógon em pastos com diferentes ofertas de forragem sob lotação contínua por caprinos.

\begin{tabular}{lcccc}
\hline \multirow{2}{*}{ Parâmetros morfogênicos e estruturais* } & \multicolumn{3}{c}{ Ofertas de forragem (\%) } & \multirow{2}{*}{ EPM** } \\
\cline { 2 - 3 } & 11 & 15 & 19 & \\
\hline $\mathrm{TApF}^{1}$ (folhas/perfilho.dia) & $0,14^{\mathrm{a}}$ & $0,13^{\mathrm{ab}}$ & $0,11^{\mathrm{b}}$ & 0,02 \\
$\mathrm{FIL}^{1}$ (dias/folha. perfilho) & $7,73^{\mathrm{b}}$ & $8,83^{\mathrm{ab}}$ & $10,52^{\mathrm{a}}$ & 1,87 \\
$\mathrm{TAlC}^{2}$ (cm/perfilho.dia) & $0,61^{\mathrm{b}}$ & $0,85^{\mathrm{b}}$ & $1,07^{\mathrm{a}}$ & 0,49 \\
$\mathrm{TAlF}^{1}$ (cm/folha.dia) & $3,31^{\mathrm{a}}$ & $3,25^{\mathrm{a}}$ & $3,16^{\mathrm{a}}$ & 0,87 \\
$\mathrm{NFVe}^{1}$ (folhas/perfilho) & $3,80^{\mathrm{a}}$ & $3,59^{\mathrm{a}}$ & $4,22^{\mathrm{a}}$ & 0,91 \\
$\mathrm{DVF}^{1}$ (dias) & $29,4^{\mathrm{b}}$ & $31,7^{\mathrm{b}}$ & $44,4^{\mathrm{a}}$ & 7,81 \\
$\mathrm{TSF}^{2}$ (cm/perfilho.dia) & $0,60^{\mathrm{a}}$ & $0,79^{\mathrm{a}}$ & $0,93^{\mathrm{a}}$ & 0,39 \\
$\mathrm{ALT}^{2}$ (cm) & $85,30^{\mathrm{b}}$ & $75,82^{\mathrm{b}}$ & $132,65^{\mathrm{a}}$ & 19,93 \\
$\mathrm{CFF}^{1}(\mathrm{~cm})$ & $41,07^{\mathrm{b}}$ & $42,82^{\mathrm{b}}$ & $49,13^{\mathrm{a}}$ & 7,44 \\
$\mathrm{CFC}^{1}(\mathrm{~cm})$ & $31,87^{\mathrm{b}}$ & $31,28^{\mathrm{b}}$ & $44,31^{\mathrm{a}}$ & 10,23 \\
\hline
\end{tabular}

${ }^{*} \mathrm{TApF}=$ taxa de aparecimento foliar; FIL = filocrono; TAlC = taxa de alongamento de colmo; TAlF = taxa de alongamento foliar; $\mathrm{NFVe}=$ número de folha vivas expandidas; DVF = duração de vida das folhas; TSF = taxa de senescência foliar; ALT = altura do dossel; $\mathrm{CFF}=$ comprimento final das folhas; $\mathrm{CFC}=$ comprimento final do colmo.

**EPM = erro padrão da média.

${ }^{1}$ Médias seguidas da mesma letra na linha não diferem $(\mathrm{P}>0,05)$ pelo teste SNK.

${ }^{2}$ Médias seguidas da mesma letra na linha não diferem $(\mathrm{P}>0,05)$ pelo teste de Duncan.

Fonte: Elaboração dos autores.

A altura do dossel dos pastos foi menor nas ofertas de forragem 11 e $15 \%$ do PV (Tabela 1), consequentemente, com perfilhos de menor tamanho e, dessa forma, as lâminas foliares mais jovens fizeram curto percurso no colmo para se expor, pois a distância percorrida pela folha, do ponto de conexão com o meristema até a extremidade do colmo, foi menor. Com isso, o tempo necessário para a visualização de uma nova folha emergida foi menor, resultando em maior TApF e menor filocrono (FIL).O contrário foi observado no pasto com maior oferta de forragem, com maior altura, perfilhos com colmos mais longos e, por isso, o percurso das lâminas foliares em expansão até sua emergência foi maior, resultando em maior FIL e menor TApF. Esses resultados estão de acordo com Fournier et al. (2005), pois o intervalo de tempo necessário para o aparecimento de duas folhas consecutivas está diretamente relacionado ao tempo de alongamento das folhas, dependente do comprimento da bainha.

A maior TApF e o menor FIL nos pastos de capim-andropógon com menor oferta de forragem (OF) e também menor altura do dossel, podem ser justificadas pela maior luminosidade no interior do dossel até a base da planta, estimulando a produção de folhas, provavelmente em decorrência da menor interceptação luminosa, pois, de acordo com 
Frank e Hofman (1994) a TApF está diretamente relacionada à taxa de interceptação luminosa.

O pasto manejado para oferta de forragem $19 \%$ do PV apresentou maior taxa de alongamento de colmo (TAlC), com 1,07 cm/perfilho.dia, em média $0,34 \mathrm{~cm}$ maior que nas outras ofertas, resultado da competição por luz entre os perfilhos. Nessa condição de maior oferta, a planta prioriza a alocação de carboidratos no alongamento dos entrenós, para posicionar a nova área foliar nas camadas menos sombreadas do dossel (LEMAIRE, 2001).

A oferta de forragem não influenciou $(\mathrm{P}>0,05)$ a taxa de alongamento foliar (TAlF), o número de folhas vivas expandidas por perfilho (NFVe) e taxa de senescência foliar (TSF), com médias 3,27 \pm 0,87 cm/perfilho.dia, 3,87 $\pm 0,91$ folhas/perfilho, $0,77 \pm 0,39 \mathrm{~cm} /$ perfilho.dia, respectivamente. Casagrande et al. (2010) ao avaliarem ofertas de forragem entre 4 e $13 \%$ do PV para bovinos em pastagem de capim-marandu e Santos et al. (2011a) ao avaliarem alturas de pastejo sob lotação contínua por bovinos com a mesma gramínea não observaram mudanças significativas na TAlF.

A média para TAlF $(3,27 \mathrm{~cm} /$ perfilho.dia $)$ foi 4,5 vezes superior à para TAlC $(0,73 \mathrm{~cm} /$ perfilho. dia) para a oferta de forragem 11 e $15 \%$ do PV, o que indica grande participação relativa de lâminas foliares e menor contribuição de colmo no crescimento do perfilho do capim-andropógon. A lâmina foliar é o elemento morfológico da planta de melhor valor nutritivo e preferencialmente consumido por caprinos em pastejo, principalmente sob menores alturas (RIBEIRO et al., 2012).

A duração de vida das folhas (DVF) foi menor nas ofertas de forragem 11 e $15 \%$ do PV em comparação à de 19\% do PV (Tabela 1), o que sugere maior renovação de tecidos sob condições de desfolhação mais severa. A maior DVF verificada no pasto de capim-andropógon manejado sob a maior oferta de forragem pode ser atribuída ao maior filocrono, pois o NFVe não foi alterado pela estratégia de pastejo.
O NFVe de uma espécie é determinado geneticamente, assumindo valor relativamente constante após o pasto atingir uma condição de equilíbrio, em que os processos de aparecimento e morte das folhas são sincronizados, podendo variar com as condições de meio e de manejo da pastagem (LEMAIRE; CHAPMAN, 1996).

A ausência de efeito da oferta de forragem sobre o NFVe pode ter decorrido da plasticidade fenotípica do capim-andropógon, que alterou sua morfogênese por meio de ajustes nas taxas de aparecimento foliar e duração de vida das folhas (Tabela 1) de forma a manter relativamente estável o número de folha viva por perfilho. Esses resultados estão de acordo com os obtidos por Santos et al. (2011a), que não observaram efeito do aumento da altura do pasto de capim Brachiaria decumbens no NFVe, com média de 4,3 folhas.

O maior comprimento final das folhas (CFF) foi observado no pasto com oferta de forragem de $19 \%$ do PV $(49,13 \mathrm{~cm})$. No entanto, entre ofertas de forragem 11 e $15 \%$ do PV não foram observadas

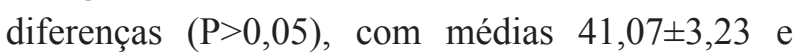
$42,82 \pm 4,56 \mathrm{~cm}$, respectivamente. Esse resultado é decorrente do menor comprimento da bainha foliar, devido à redução da fase de multiplicação celular, que resulta em menor CFF (DURU; DUCROCQ, 2000b), ocasionado pela desfolhação mais intensa quando da menor oferta de forragem. Há relação positiva entre o aumento da oferta de forragem em pastagens de gramíneas e altura de pastejo com o CFF (CASAGRANDE et al., 2010; SANTOS et al., 2011a, 2011b).

O comprimento final do colmo (CP) foi maior $(\mathrm{P}<0,05)$ na oferta de forragem $19 \%$ do PV. Para as

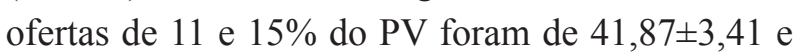
$42,82 \pm 4,10 \mathrm{~cm}$, respectivamente (Tabela 1 ). Esses resultados podem estar relacionados ao fato de que plantas submetidas à maior oferta de forragem apresentaram perfilhos com colmo em estádio de desenvolvimento mais avançado. Além disso, o aumento da TAlC, como resposta fisiológica dos 
perfilhos ao sombreamento, comum nos pastos mais altos, também justificam o maior comprimento final do colmo pois resulta na exposição de folhas jovens, parte mais fotossinteticamente ativa da planta, na região superior do dossel (PERI; LUCAS; MOOT, 2007).

O maior comprimento do colmo dos perfilhos nos pastos com oferta de forragem 19\% do PV é indício de que a estrutura do capim-andropógon pode tornar-se desfavorável ao consumo animal (FLORES et al., 2008), bem como pode ser um parâmetro de decréscimo do valor nutritivo do pasto (SANTOS et al., 2008), devido aos maiores teores de fibra e menores teores de proteína bruta.

Não houve interação $(P>0,05)$ entre as ofertas de forragem e os períodos de pastejo para a densidade populacional de perfilhos basais vegetativos, com uma média de $1.732 \pm 575$ perfilhos $/ \mathrm{m}^{2}$ (Tabela 2). A manutenção de alturas elevadas em todos os pastos, provavelmente não proporcionou mudanças na penetração de luz no dossel considerando as OF e os meses, e deste modo não influenciou a densidade populacional de perfilhos. Segundo Robson, Ryle e Woledge (1988) o perfilhamento é estimulado por altos níveis de radiação solar incidente e pela relação luz vermelha e infravermelha.

Tabela 2. Densidade populacional de perfilhos basais vegetativos e reprodutivos em pasto de capim-andropógon em diferentes períodos de pastejo e oferta de forragem sob lotação contínua por caprinos.

\begin{tabular}{|c|c|c|c|c|c|}
\hline \multirow{2}{*}{ Períodos de pastejo } & \multicolumn{3}{|c|}{ Oferta de forragem $(\%)$} & \multirow{2}{*}{ Médias } & \multirow{2}{*}{$\mathrm{EPM}^{* *}$} \\
\hline & 11 & 15 & 19 & & \\
\hline & \multicolumn{3}{|c|}{$\operatorname{DPPv}^{1}$ (perfilhos $\left./ \mathrm{m}^{2}\right)$} & & \multirow{5}{*}{575} \\
\hline $8 / 4$ a $5 / 5 / 11$ & 1.560 & 1.770 & 1.594 & $1.641^{\mathrm{A}^{*}}$ & \\
\hline $5 / 5$ a $1 / 6 / 11$ & 1.652 & 1.972 & 1.582 & $1.735^{\mathrm{A}}$ & \\
\hline $1 / 6$ a $29 / 6 / 11$ & 1.710 & 1.714 & 2.038 & $1.821^{\mathrm{A}}$ & \\
\hline \multirow[t]{2}{*}{ Médias } & $1.641^{\mathrm{a}}$ & $1.819^{\mathrm{a}}$ & $1.738^{\mathrm{a}}$ & & \\
\hline & \multicolumn{3}{|c|}{ DPPf (perfilhos $/ \mathrm{m}^{2}$ ) } & & \multirow{5}{*}{174} \\
\hline $8 / 4$ a $5 / 5 / 11$ & 92 & 26 & 148 & $89^{\mathrm{A}}$ & \\
\hline $5 / 5$ a $1 / 6 / 11$ & 0 & 0 & 254 & $85^{\mathrm{A}}$ & \\
\hline $1 / 6$ a $29 / 6 / 11$ & 0 & 0 & 0 & $0^{\mathrm{A}}$ & \\
\hline Médias & $31^{\mathrm{b}}$ & $9^{\mathrm{b}}$ & $134^{\mathrm{a}}$ & & \\
\hline
\end{tabular}

**Erro padrão da média.

${ }^{1} \mathrm{DPPV}=$ densidade populacional de perfilhos vegetativos; $\mathrm{DPPf}=$ densidade populacional de perfilhos reprodutivos.

*Médias seguidas de mesma letra minúscula na linha e maiúscula na coluna não diferem entre si $(\mathrm{P}>0,05)$ pelo teste $\mathrm{t}$.

Fonte: Elaboração dos autores.

Não houve efeito $(\mathrm{P}>0,05)$ dos períodos de pastejo sobre o número de perfilhos reprodutivos (Tabela 2), com média $86,6 \pm 174$ perfilhos $/ \mathrm{m}^{2}$, correspondendo a apenas $4,76 \%$ do total de perfilhos. Verificou-se maior $(\mathrm{P}>0,05)$ número de perfilhos reprodutivos quando da oferta de forragem 19\% do PV, devido, possivelmente, à menor intensidade de desfolha nos pastos com maior oferta de forragem o que fez com que muitos perfilhos escapassem do pastejo, proporcionando maior número de perfilhos que passam do estádio vegetativo para o reprodutivo, de acordo com o ciclo fenológico normal das gramíneas (LEMAIRE; CHAPMAN, 1996).

Não houve efeito da oferta de forragem $(\mathrm{P}>0,05)$ sobre a taxa de aparecimento de perfilhos basais (TApPb), com média $17,83 \%$, embora se tenha verificado efeito do período de pastejo $(\mathrm{P}<0,05)$ (Tabela 3). 
Tabela 3. Taxas de aparecimento, mortalidade e sobrevivência de perfilhos basilares em pasto de capim-andropógon em diferentes períodos de pastejo e ofertas de forragem sob lotação contínua por caprinos.

\begin{tabular}{|c|c|c|c|c|c|}
\hline \multirow{2}{*}{ Períodos de pastejo } & \multicolumn{3}{|c|}{ Oferta de forragem $(\%)$} & \multirow{2}{*}{ Médias } & \multirow{2}{*}{$\mathbf{E P M}^{* *}$} \\
\hline & 11 & 15 & 19 & & \\
\hline & \multicolumn{3}{|c|}{$\mathrm{TApPb}^{1}(\%)$} & & \multirow{5}{*}{13,8} \\
\hline $8 / 4$ a $5 / 5 / 11$ & 17,0 & 9,3 & 2,0 & $9,4^{\mathrm{B}^{*}}$ & \\
\hline $5 / 5$ a $1 / 6 / 11$ & 27,8 & 30,1 & 28,8 & $28,9^{\mathrm{A}}$ & \\
\hline $1 / 6$ a $29 / 6 / 11$ & 11,2 & 14,5 & 19,4 & $15,0^{\mathrm{B}}$ & \\
\hline Médias & $18,7^{\mathrm{a}^{*}}$ & $18,0^{\mathrm{a}}$ & $16,8^{\mathrm{a}}$ & & \\
\hline & \multicolumn{3}{|c|}{$\mathrm{TMoPb}(\%)$} & & \multirow{5}{*}{6,6} \\
\hline $8 / 4$ a $5 / 5 / 11$ & 7,3 & 7,6 & 11,6 & $8,8^{\mathrm{A}}$ & \\
\hline $5 / 5$ a $1 / 6 / 11$ & 6,6 & 10,1 & 13,9 & $10,2^{\mathrm{A}}$ & \\
\hline $1 / 6$ a $29 / 6 / 11$ & 6,7 & 12,7 & 7,9 & $9,1^{\mathrm{A}}$ & \\
\hline Médias & $6,8^{\mathrm{a}}$ & $10,14^{\mathrm{a}}$ & $11,2^{\mathrm{a}}$ & & \\
\hline & \multicolumn{3}{|c|}{ TSoPb (\%) } & & \multirow{5}{*}{6,6} \\
\hline $8 / 4$ a $5 / 5 / 11$ & 92,7 & 92,4 & 88,3 & $91,1^{\mathrm{A}}$ & \\
\hline $5 / 5$ a $1 / 6 / 11$ & 93,4 & 89,9 & 86,0 & $89,8^{\mathrm{A}}$ & \\
\hline $1 / 6$ a $29 / 6 / 11$ & 93,3 & 87,2 & 92,0 & $90,8^{\mathrm{A}}$ & \\
\hline Médias & $93,1^{\text {a }}$ & $89,8^{\mathrm{a}}$ & $88,8^{\mathrm{a}}$ & & \\
\hline
\end{tabular}

**EPM $=$ erro padrão da média.

${ }^{1} \mathrm{TApPb}=$ taxa de aparecimento de perfilhos basilares; $\mathrm{TMoPb}=$ taxa de mortalidade de perfilhos basilares; $\mathrm{TSoPb}=$ taxa de sobrevivência de perfilhos basilares.

*Médias seguidas de mesma letra minúscula na linha e maiúscula na coluna não diferem entre si $(\mathrm{P}>0,05)$ pelo teste t.

Fonte: Elaboração dos autores.

As menores $\mathrm{TApPb}$ ocorreram nos meses de abril e junho, enquanto a maior $\mathrm{TApPb}$ ocorreu no mês de maio (Tabela 3 ). A menor TApPb no mês de abril pode ser associada à elevada altura do pasto, $128,2 \mathrm{~cm}$, uma vez que as condições ambientais eram favoráveis ao crescimento do pasto, considerando a disponibilidade hídrica (Figura 1). A altura do dossel provavelmente provocou maior sombreamento na base das plantas, o que inibiu o perfilhamento do capimandropógon. O sombreamento é um fator de inibição de perfilhamento, pois nesta situação, a maior quantidade de assimilados é alocada para o crescimento dos perfilhos existentes em prejuízo do desenvolvimento de novos perfilhos segundo (SANTOS et al., 2010). Em junho, com a diminuição da precipitação pluviométrica, apenas $70 \mathrm{~mm}$, concentrada em três dias, houve decréscimo do aparecimento de novos perfilhos.
Quando fatores de crescimento, como luz, água ou disponibilidade de nutrientes são restringidos, a produção de perfilhos é comprometida, em decorrência do baixo estoque de carboidratos não estruturais na base do colmo (TURNER et al., 2006).

Durante todo o período de pastejo, independente da oferta de forragem, $\mathrm{a} \mathrm{TApPb}$ foi superior à taxa de mortalidade de perfilhos basilares (TMoPb), o que indica renovação de perfilhos no pasto de capim-andropógon. De forma geral, espera-se que a renovação de perfilhos supere a para que a taxa de mortalidade, pois a manutenção da densidade populacional de perfilhos é o resultado do balanço entre estas taxas em um dado ambiente e condição de manejo da pastagem (SANTOS et al., 2011c).

$\mathrm{A} \mathrm{TMoPb}$ e a $\mathrm{TSoPb})$ não variaram $(\mathrm{P}>0,05)$ com a oferta de forragem e períodos de pastejo, 
com médias 9,4 e 90,6\%, respectivamente (Tabela 3). A elevada $\mathrm{TSoPb}$ do capim-andropógon observada é reflexo da menor $\mathrm{TMoPb}$. Essa é uma característica que deve ser melhor explorada no manejo da pastagem, por demonstrar boa longevidade da planta, o que poderá garantir produção de forragem nova até a estação seca seguinte.
Houve efeito $(\mathrm{P}<0,05)$ da oferta de forragem e período de pastejo para o índice de estabilidade (IEst) do pasto (Tabela 4), o qual reflete o aparecimento e a sobrevivência de perfilhos. O maior IEst foi verificado em maio, devido à maior $\mathrm{TApPb}$ (Tabela 4), enquanto a oferta $11 \%$ de forragem resultou em maior IEst, em decorrência da maior $\mathrm{TApPb}$ e $\mathrm{TSoPb}$.

Tabela 4. Índice de estabilidade de pastos de capim-andropógon em diferentes períodos de pastejo e ofertas de forragem sob lotação contínua por caprinos.

\begin{tabular}{cccccc}
\hline \multirow{2}{*}{ Períodos de pastejo } & \multicolumn{3}{c}{ Oferta de forragem $(\%)$} & \multirow{2}{*}{ Médias } & \multirow{2}{*}{ EPM $^{* *}$} \\
\cline { 2 - 3 } & 11 & 15 & 19 & $1,01^{\mathrm{B}^{*}}$ & \\
\cline { 2 - 4 } $8 / 4$ a $5 / 5 / 11$ & 1,12 & 1,01 & 0,90 & $1,16^{\mathrm{A}}$ & 0,15 \\
$5 / 5$ a $1 / 6 / 11$ & 1,20 & 1,16 & 1,11 & $1,05^{\mathrm{B}}$ & \\
$1 / 6$ a $29 / 6 / 11$ & 1,04 & 1,00 & 1,10 & & \\
Médias & $1,12^{\mathrm{a}^{*}}$ & $1,06^{\mathrm{b}}$ & $1,04^{\mathrm{b}}$ & \\
\hline
\end{tabular}

**EPM $=$ erro padrão da média.

${ }^{1}$ IEst $=$ índice de estabilidade.

*Médias seguidas de mesma letra minúscula na linha e maiúscula na coluna não diferem entre si $(\mathrm{P}>0,05)$, pelo teste t.

Fonte: Elaboração dos autores.

O IEst do capim-andropógon nos meses de abril e junho e para as ofertas de forragem 15 e $19 \%$ do PV manteve-se próximo a 1,0, indicando estabilidade do pasto sob estas condições. Contudo, no mês de maio, o IEst foi superior a 1,0, indicando que a sobrevivência aliada ao aparecimento de novos perfilhos foi suficiente para compensar a $\mathrm{TMoPb}$. Estes resultados para IEst demonstram haver um mecanismo compensatório entre a $\mathrm{TApPb}$ e a $\mathrm{TMoPb}$ nos pastos de capim-andropógon, que tende a estabilizar a população de perfilhos e garantir sua persistência na área utilizada sob pastejo por caprinos no período chuvoso. Índices de estabilidade maiores que 1,0, também foram encontrados por Calvano et al. (2011) em estudo de diferentes intensidades de pastejo com capimmarandu.

\section{Conclusões}

O manejo do pasto de capim-andropógon sob lotação contínua por caprinos com oferta de forragem 11\% do PV aumenta a taxa de aparecimento de folhas. A oferta de forragem 19\% do PV resulta no aumento da taxa de alongamento do colmo, na duração de vida das folhas e no comprimento das folhas e colmos. As ofertas de forragem de 11 a $19 \%$ do PV não influenciam o número de perfilhos vegetativos e as taxas de aparecimento e sobrevivência de perfilhos em pasto de capim-andropógon manejado sob lotação contínua por caprinos. 


\section{Referências}

ALLEN, V. G.; BATELLO, C.; BERRETTA, E. J. A.; HODGSON, J.; KOTHMANN, M.; LI, X.; MCIVOR, J.; MILNE, J.; MORRIS, C.; PEETERS, A.; SANDERSON, M. An international terminology for grazing lands and grazing animals. Grass and Forage Science, Oxford, v. 66, n. 1, p. 2-28, 2011.

BAHMANI, I.; THOM, E. R.; MATTHEW, C.; HOOPER, R. J.; LEMAIRE, G. Tiller dynamics of perennial ryegrass cultivars derived from different New Zealand ecotypes: effects of cultivars, season, nitrogen fertilizer, and irrigation. Australian Journal of Agricultural Research, Victoria, v. 54, n. 8, p. 803-817, 2003.

BARBOSA, M. A. A de F.; NASCIMENTO, J.; CECATO, U. Dinâmica da pastagem e desempenho de novilhos em pastagem de capim tanzânia sob diferentes ofertas de forragem. Revista Brasileira de Zootecnia, Viçosa, MG, v. 35, n. 4, p. 1594-1600, 2006.

BARBOSA, R. A.; NASCIMENTO JÚNIOR, D.; VILELA, H. H.; SILVA, S. C. da; EUCLIDES, V. P. B.; SBRISSIA, A. F.; SOUSA, B. M. L. Morphogenic and structural characteristics of guinea grass pastures submitted to three frequencies and two defoliation severities. Revista Brasileira de Zootecnia, Viçosa, MG, v. 40, n. 5, p. 947-954, 2011.

BASSO, K. C.; CECATO, U.; LUGÃO, S. M. B.; GOMES, J. A. M.; BARBERO, L. M.; MOURÃO, G. B. Morfogênese e dinâmica do perfilhamento em pastos de Panicum maximum Jacq. cv. IPR-86 Milênio submetido a doses de nitrogênio. Revista Brasileira de Saúde e Produção Animal, Salvador, v. 11, n. 4, p. 976-989, 2010.

CALVANO, M. P. C. A.; EUClidES, V. P. B.; MONTAGNER, D. B.; LEMPP, B.; DIFANTE, G. S.; FLORES, R. S.; GALBEIRO, S. Tillering and forage accumulation in Marandu Grass under different grazing intensities. Revista Ceres, Viçosa, MG, v. 58, n. 6, p. 781789, 2011.

CARVALHO, C. A. B.; SILVA, C. da; SBRISSIA, A. F.; PINTO, F. M.; CARNEVALLI, R. A.; FAGUNDES, J. L.; PEDREIRA, C. G. S. Demografia do perfilhamento e taxas de acúmulo de matéria seca em capim 'tifton 85 ' sob pastejo. Scientia Agricola, Piracicaba, v. 57, n. 4, p. 591-600, 2000.

CASAGRANDE, D. R.; RUGGIERI, A. C.; JANUSCKIEWICZ, E. R.; GOMIDE, J. A.; REIS, R. A.; VALENTE, A. L. S. Características morfogênicas e estruturais do capim-marandu manejado sob pastejo intermitente com diferentes ofertas de forragem. Revista da Sociedade Brasileira de Zootecnia, Viçosa, MG, v. 39, n. 10, p. 2108-2115, 2010.
CHAPMAN, D. F.; LEMAIRE, G. Morphogenetic and structural determinants of plant regrownth after defoliation. In: INTERNATIONAL GRASSLAND CONGRESS, 17., 1993, Palmerston North.Proceedings... Palmerston North: New Zealand Grassland Association, 1993. p. 95-104.

DONEDA, G. Z.; SANTOS, G. T.; SBRISSIA, A. F. Frequencies and intensities of defoliation in Aruana Guineagrass swards: accumulation and morphological composition of forage. Revista da Sociedade Brasileira de Zootecnia, Viçosa, MG, v. 41, n. 4, p. 905-913, 2012.

DURU, M.; DUCROCQ, H. Growth and senescence of the successive leaves on a cocksfoot tiller. Effect of nitrogen and cutting regime. Annals of Botany, Oxford, v. 85, n. 5 , p. $645-653,2000$ b.

Growth and senescence of the successive grass leaves on a tiller. Ontogenic development and effect of temperature. Annals of Botany, Oxford, v. 85, n. 5, p. 635-643, 2000a.

EMPRESA BRASILEIRA DE PESQUISA AGROPECUÁRIA - EMBRAPA. Centro Nacional de Pesquisa de Solos. Sistema brasileiro de classificação de solos. 2. ed. Rio de Janeiro: EMBERAPA, 2006. 412 p.

FERLIN, M. B.; EUCLIDES, V. P. B.; LEMPP, B.; GONÇALVES, M. C.; CUBAS, A. C. Morfogênese e dinâmica de perfilhamento de Panicum maximum Jacq. cv. Tanzânia-I sob pastejo. Ciência e Agrotecnologia, Lavras, v. 30, n. 2, p. 44-352, 2006.

FLORES, R. S.; EUCLIDES, V. P. B.; ABRÃO, M. P. C.; GALBEIRO, S.; DIFANTE, G. S.; BARBOSA, R. A. Desempenho animal, produção de forragem e características estruturais dos capins marandu e xaraés submetidos a intensidade de pastejo. Revista Brasileira de Zootecnia, Viçosa, MG, v. 37, n. 8, p. 1355-1365, 2008.

FOURNIER, C.; DURAND, J. L.; LJUTOVAC, S.; SCHÄUFELE, R.; GASTAL, F.; ANDRIEU, B. functional-structural model of elongation of the grass leaf and its relationships with the phyllochron. New Phytologist, Lancaster, v. 166, n. 3, p. 881-894, 2005.

FRANK, A. B.; HOFMAN, L. Light quality and stem numbers in cool-season forage grasses. Crop Science, Madison, v. 34, n. 2, p. 468-473, 1994.

LEMAIRE, G. Ecophysiology of grasslands: dymamics aspects of forage plant populations in grazed swards. In: INTERNATIONAL GRASSLAND CONGRESS, 19., 2001, São Pedro. Proceedings... São Pedro: Fundação de Estudos Agrários Luiz de Queiroz, 2001. p. 29-37. 
LEMAIRE, G.; CHAPMAN, D. Tissue flows in grazed plant communities. In: HODGSON, J.; ILLIUS, W. (Ed.). The ecology and management of grazing systems. CAB International, Wallingford, UK, 1996. p. 3-36.

MOTT, G. O.; LUCAS, H. L. The design, conduct and interpretation of grazing trials in cultivated and improved pastures. In: INTERNATIONAL GRASSLAND CONGRESS, 6., 1952, Pasadena. Proceedings... Pasadena: Estate College Press, 1952. p. 1380-1385.

PERI, P. L.; LUCAS, R. J.; MOOT, D. J. Dry matter production, morphology and nutritive value of Dactylis glomerata growing under different light regimes. Agroforestry Systems, Dodrecht, v. 70, n. 1, p. 63-79, 2007.

RIBEIRO, A. M.; OLIVEIRA, M. E.; SILVA, P. C.; RUFINO, M. O. A.; RODRIGUES, M. M.; SANTOS, M. S. Canopy characteristics, animal behavior and forage intake by goats grazing on Tanzania-grass pasture with different heights. Revista Acta Scientiarum Animal Sciences, Maringá, v. 34, n. 4, p. 371-378, 2012.

ROBSON, M. J.; RYLE, G. J. A.; WOLEDGE, J. The grass plant - its form and function. In: JONES, M. B.; LAZENBAY, A. (Ed.). The grass crop: the physiological basis of production. London: Chapman and Hall, 1988. v. 2 , p. $25-83$.

ROMA, C. F. C.; CECATO, U.; SOARES FILHO, C. V.; SANTOS, G. T.; RIBEIRO, O. L.; IWAMOTO, B. S. Morphogenetic and tillering dynamics in Tanzania grass fertilized and non-fertilized with nitrogen according to season. Revista Brasileira de Zootecnia, Viçosa, MG, v. 41, n. 3, p. 565-573, 2012.

SANTOS, M. E. R.; FONSECA, D. M.; BALBINO, E. M.; EUCLIDES, V. P. B.; RIBEIRO JÚNIOR, J. I.; CASAGRANDE, D. R. Valor nutritivo da forragem e de seus componentes morfológicos em pastagens de Brachiaria decumbens diferida. Boletim da Indústria Animal, Nova Odessa, v. 65, n. 4, p. 303-311, 2008.
SANTOS, M. E. R.; FONSECA, D. M.; BRAZ, T. G. S.; GOMES, V. M.; SILVA, G. P. Características morfogênicas e estruturais de perfilhos de capimbraquiária em locais do pasto com alturas variáveis. Revista Brasileira de Zootecnia, Viçosa, MG, v. 40, n. 3, p. 535-542, 2011a.

SANTOS, M. E. R.; FONSECA, D. M.; GOMES, V. M.; BALBINO, E. M.; MAGALHÃES, M. A. Estrutura do capim-braquiária durante o diferimento da pastagem. Acta Scientiarum. Animal Sciences, Maringá, v. 32, n. 2, p. 139-145, 2010.

SANTOS, M. E. R.; FONSECA, D. M.; GOMES, V. M.; NASCIMENTO JÚNIOR, D.; GOMIDE, C. A. M.; SBRISSIA, A. F. Capim-braquiária sob lotação contínua e com altura única ou variável durante as estações do ano: dinâmica do perfilhamento. Revista da Sociedade Brasileira de Zootecnia, Viçosa, MG, v. 40, n. 11, p. 2332-2339, 2011c.

Capim-braquiária sob lotação contínua e com altura única ou variável durante as estações do ano: morfogênese e dinâmica de tecidos. Revista Brasileira de Zootecnia, Viçosa, MG, v. 40, n. 11, p. 2323-2331, $2011 \mathrm{~b}$.

SILVEIRA, M. C. T.; NASCIMENTO JÚNIOR, D.; SILVA, S. C. da; EUCLIDES, V. P. B.; MONTAGNER, D. B.; SBRISSIA, A. F.; RODRIGUES, C. A. S.; SOUSA, B. M. L.; SILVA, K. P. da; VILELA, H. H. Morphogenetic and structural comparative characterization of tropical forage grass cultivars under free growth. Scientia Agrícola, Piracicaba, v. 67, n. 2, p. 136-142, 2010.

TURNER, L. R.; DONAGHY, D. J.; LANE, P. A.; RAWNLEY, R. P. Effect of defoliation on water-soluble carbohydrate and nitrogen energy reserves, regrwth of leaves and roots, and tiller number of cocksfoot (Dacttylis glomerata L.) plants. Australian Journal of Agricultural Research, Victoria, v. 57, n. 2, p. 243-249, 2006. 